Clemson University

TigerPrints

$1-2021$

Experimental Methods to Capture Curing Induced Effects in Adhesive Bonded Joints

Akshat Agha

Fadi Abu-Farha

Follow this and additional works at: https://tigerprints.clemson.edu/auto_eng_pub

Part of the Automotive Engineering Commons 


\title{
Experimental Methods to Capture Curing Induced Effects in Adhesive Bonded Joints
}

\author{
Akshat Agha*1, Fadi Abu-Farha ${ }^{1}$ \\ ${ }^{1}$ Clemson University- International Center for Automotive Research (CU-ICAR), 4 Research Drive, \\ Greenville, SC 29607, USA \\ *Corresponding Author. Tel +1 (336) 346 4213; E-mail: aagha@clemson.edu
}

\begin{abstract}
The rapidly increasing use of structural adhesives, especially in the joining of automotive body structures has motivated various investigations of the effects of adhesive curing process on joints. The automotivegrade structural adhesives require heat curing, which, in the meantime, performs thermal loading on the substrates and causes undesirable effects in the joint. For example, the curing process results in complex residual stresses in the adhesive bond which are detrimental to the performance of the adhesive bond and thereby the automobile body structure, particularly the crashworthiness. To thoroughly evaluate such effects, this paper consists of two parts. The first part presents an innovative experimental method to characterize the thermal effects of the heat curing process on a multi-material single lap shear joint using digital image correlation. The second part of the study compares the performance of residual stressinduced joints against stress-free joints under tension loading at different strain rates. The proposed experimental method and the corresponding results from this study are expected to help comprehensively understand the adhesive joining process and its potential side effects on the automobile body structure.
\end{abstract}

\section{KEYWORDS}

Curing, structural adhesives, automotive, multi-material joints, residual stress, viscoelastic, digital image correlation 


\section{INTRODUCTION}

Enhanced concerns associated with increasing levels of emission of local pollutants (such as $\mathrm{SO}_{2}$ and NOX) and global greenhouse gases (such as $\mathrm{CO}_{2}$ ) have driven the automotive industry towards producing enhanced fuel-efficient vehicles. Among various strategies, vehicle lightweighting is considered as one of the most effective and thus attractive choices. In a steel-dominant automotive body, significant weight reduction is achievable by low-density material substitution [1, 2]. Nevertheless, most lightweight materials, such as aluminum and reinforced plastics, usually company with increased prices. Based on a balanced consideration, multi-material body construction is thereby frequently adopted in the automotive industry. However, this solution is strongly limited by the difficulties of multi-material joining using conventional joining techniques (like spot-welding) [3, 4].

As an alternative, adhesive bonding is applicable for joining dissimilar materials, such as ferrous metals, non-ferrous metals, and fiber-reinforced plastics. Such a method not only enables high-performance and flexible joints but also eliminates the weight and cost of fasteners, such as bolts, screws, and rivets, associated with mechanical joining techniques $[5,6]$. Therefore, structural adhesives and sealants have been used extensively in automotive body structures and such a trend continues to grow. Nevertheless, the fact that automotive structural adhesives are single component adhesives, which need to be heat cured (except 2-component adhesives used for CFRP parts) accounts for a critical problem: the difference in the coefficients of thermal expansion (CTE) of the joined parts has significant implications on the integrity and response of the Body-in-white (BIW) to external loading, especially thermal loading.

Furthermore, as per the current trend in the automotive industry, the adhesive heat curing process is combined with the automotive paint baking process based on the considerations of manufacturing process efficiency and economy [7]. At elevated temperature in the paint baking oven, different components of the body structure expand at different rates and magnitudes depending on their different 
CTE and air convection properties in local areas. After the adhesive is cured at the peak temperature, it constraints the thermal contraction in the components during the cooling down phase. This (when extended to all components and different joints in a BIW) leads to distortions in the structure and, more importantly, residual stresses in the adhesive-bonded joints. It is well established that the presence of such residual stresses is detrimental to the performance of the adhesive bond and thereby the automobile body structure, particularly crashworthiness.

Several efforts have experimentally shown the effects of residual stresses in adhesively bonded joints. Reedy et al. [8] studied the effect of fabrication residual stresses on the strength of a butt joint considering the stress relaxation behavior of the adhesive at different temperatures. They concluded that the effects of the stresses diminish with time due to the relaxation behavior of the adhesives. Kim and Lee [9] found that the load-bearing capacity of an adhesive bonded joint is greatly influenced by the fabrication residual thermal stresses. Apalak et al. [10] showed that the thermal mismatch between the substrates can result in huge thermal strains and affect the adhesive-bonded joint. Yu et al. [11] studied the residual stresses due to curing shrinkage and thermal expansion in epoxy-steel bi-material beams. Kropka et al. [12] investigated the role of residual stress on joint strength on a napkin-ring joint geometry. Experimental investigations done by Teutenberg [13] indicated the effect of residual stress in a lap shear joint compared to a stress-free joint at different degrees of cure of the adhesive. The results showed a considerable decrease in the displacement across the joint before fracture, along with a decrease in maximum force. Ma et al. [14] studied the effect of several curing curves on the residual stresses generated in the hightemperature phosphate adhesive-bonded joint on a single lap joint. Lucas F. M. da Silva et al.[15-17] studied the thermal residual stresses generated in the joint due to non-free thermal expansion and contraction in the joint, and also due to shrinkage of adhesives caused by the curing process. They evaluated the benefits of using a dual adhesive joint design between dissimilar materials over a wide range of temperatures, to mitigate the effects of thermal mismatch in the adhesive and adherends. The 
thermal stresses generated in the paint baking oven due to CTE mismatch or delta-alpha problem were also studied by Dietrich [18] and Regensburger [19]. They stated that the thermally induced stresses can be reduced by reducing the oven temperature and flattening the heating and the cooling cycle.

This paper presents an innovative experimental method to capture the thermal effects on the adhesivebonded joint and helps in quantifying the induced effects which will help in better understanding of the complex residual stresses generated due to the adhesive heat curing process. In this paper, two types of experiments and the corresponding results are discussed:

(i) First, a unique experimental approach is shown to capture the effects of heat curing on an adhesive bonded single lap shear joint during the curing process using 3D digital image correlation. The tests were conducted on two metal substrates combinations using an automotive-grade structural adhesive.

(ii) Second, the effects of the residual stresses on the strength of single-lap shear joints at different strain rates are discussed. The joints with residual stresses produced using the mentioned approach in (i) were tested in tension and the performance of the joints with residual stress was compared to stress-free joints. The highlight of this work is that the tests were performed at three different shear strain rates ranging from low $(0.005 / \mathrm{s})$ to high $(50 / \mathrm{s})$.

The experimental data generated by the discussed approach in this paper are expected to comprehensively reveal the thermal effects in the joint during the curing process. Furthermore, the test can be used for the validation of adhesive material models as it yields quantifiable parameters like thermal displacement and force (cause of residual stresses in the adhesive joint), which can be used for validating adhesive material models in a FE simulation. The adhesive material models can then be used for any application, including automotive. In addition, the effects of the residual stresses at different strain rates will help in studying the significance of the fabrication residual stresses at low to high strain rates, like in the case of a crash event. 


\section{EXPERIMENTS TO CAPTURE THERMAL EFFECTS DURING THE HEAT CURING PROCESS}

The automotive paint baking cycle, which is also used for curing the adhesives, lasts approximately 30 minutes. When the BIW passes through the paint baking oven, the temperature of the body structure rises to the range of $160-180^{\circ} \mathrm{C}$, and then slowly falls to the ambient level [20]. The duration and temperature of the paint baking cycle are specific to each automotive manufacturer. In this work, the test aimed to reproduce the effects caused by thermal expansion of similar and dissimilar substrates in an adhesive joint during the adhesive curing process in the automotive paint bake cycle. A testing approach was developed to capture the thermal displacements in an uncured specimen during the curing process, using Digital Image Correlation (DIC). The test results provide insight into the relative displacement of substrates during the adhesive curing process.

\subsection{Specimen geometry and materials}

The tests were conducted on adhesive bonded single lap shear joints as shown in Figure 1. Each specimen consisted of two metal substrates joined by an adhesive layer. Each substrate was $100 \mathrm{~mm}$ long and 20 $\mathrm{mm}$ wide. The overlap area of the adhesive bond was $20 \times 20 \mathrm{~mm}^{2}$. The minimum thickness of the adhesive layer was controlled by adding a $5 \%$ volume fraction of $0.30 \mathrm{~mm}$ solid glass microspheres to the adhesive. The glass microspheres ensured that the minimum adhesive bead thickness in the joint was $0.30 \mathrm{~mm}$.

The tests proceeded with two sets of substrates combinations: (i) multi-material combination of DP980 steel and aluminum alloy AA7071, referred in this paper as ST-AL; (ii) similar material combination of aluminum alloy AA7071 with itself, referred in this paper as AL-AL. The thickness of the DP980 sheet was $1.42 \mathrm{~mm}$ while the thickness of the AA7071 sheet was $2.55 \mathrm{~mm}$. The mechanical properties of the DP980 and AA7071 metal substrates at room temperature were obtained by standard uniaxial tension tests. The grade and the thickness of aluminum and steel substrates were carefully chosen to ensure that the 
substrates do not undergo excessive deformation before the joint fails, i.e. making sure that the yielding force (yield strength $x$ thickness $x$ width) for the substrates was higher than the force required for the adhesive joint to fail. The material properties obtained from the uniaxial tension tests of standard dogbone samples of the metal substrates are presented in Figure 2 as force-longitudinal strain curves to provide a better understanding of the yielding force. The material properties of the substrates are summarized in Table 2.

The adhesive used for the study was an automotive-grade structural adhesive Henkel Teroson EP 5089, provided by Henkel Corporation. It is a heat curing, single-component adhesive, based on toughened epoxy resin. It is specially developed to provide high peel and impact peel resistance over the wide temperature range and is optimized for high crash forces. The mechanical properties of the adhesive as per the technical data sheet are given in Table 1.

Table 1. Properties of the adhesive Teroson EP 5089

\begin{tabular}{|c|c|}
\hline Young's Modulus (ISO 527-1) & $1.6 \mathrm{GPa}$ \\
\hline Tensile Strength (ISO 527-1) & $35 \mathrm{MPa}$ \\
\hline Shear Strength (DIN EN 1465) & $>20 \mathrm{MPa}$ \\
\hline Elongation at break (ISO 527-1) & $10 \%$ \\
\hline Poisson Ratio & 0.4 \\
\hline
\end{tabular}




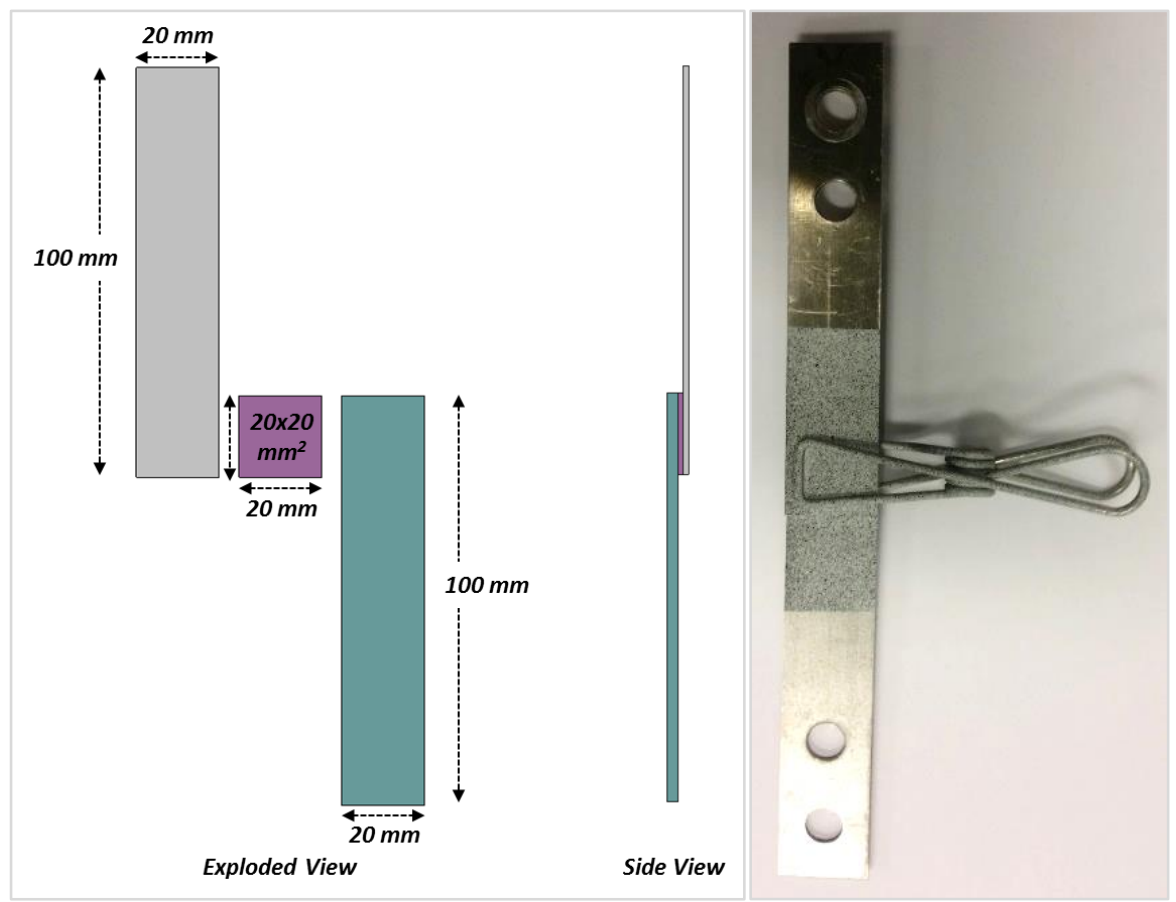

Figure 1. (a) Single lap shear joint specimen geometry, (b) an uncured specimen painted with the speckle pattern for DIC strain measurement

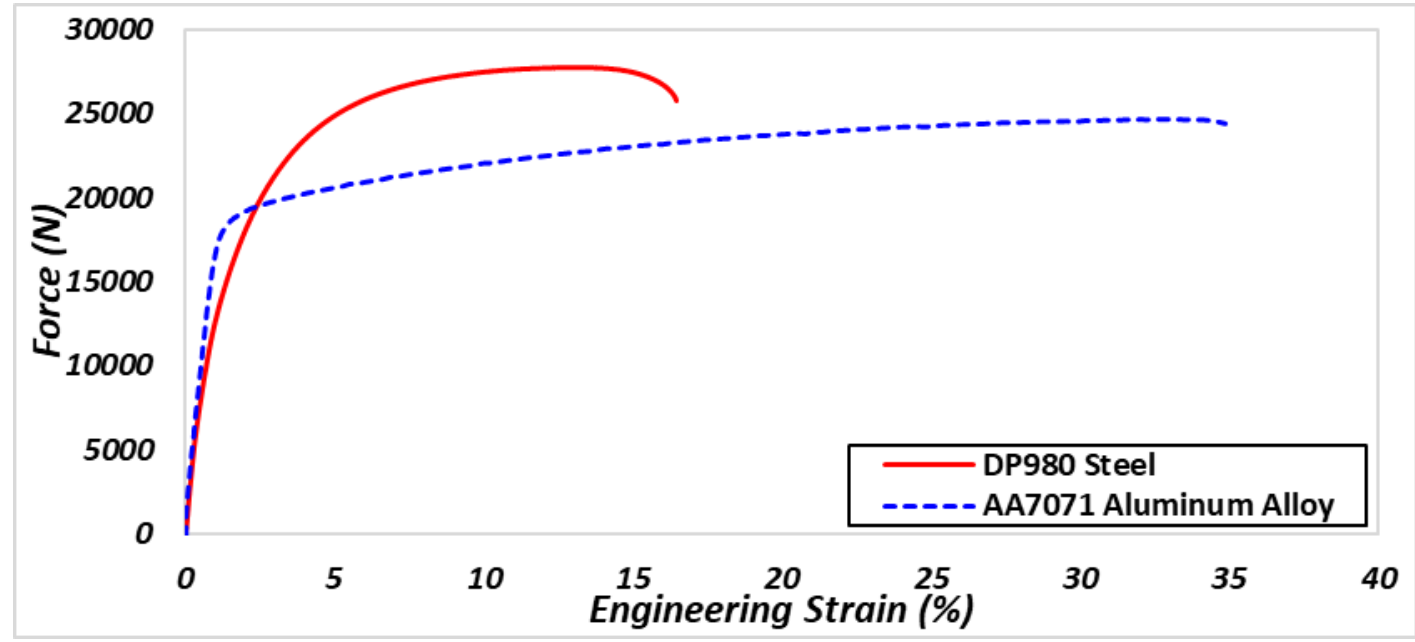

Figure 2. Force vs. strain curve obtained from uniaxial tension testing of the metal substrates - DP980 $(1.42 \mathrm{~mm})$ and $A A 7071(2.55 \mathrm{~mm})$, both $20 \mathrm{~mm}$ wide, tested at room temperature 


\subsection{Experimental setup}

The experimental setup used for testing was built on an Instron universal load frame, similar to a standard uniaxial tensile test configuration.

Furnace: The tests were performed on a specialized setup which consisted of a furnace installed on the universal load frame. The furnace was a circulating air oven that was capable of maintaining temperature consistently up to $450^{\circ} \mathrm{C}$ with minimum variation. The setup was arranged to have the mounting grips and the specimen inside the furnace to simulate automotive paint baking oven conditions. The furnace was designed to have a small glass window opening in the front door through which the specimen was monitored using the DIC system.

Grips: The grip rods used in the test were made of nickel-iron alloy (INVAR), known for its uniquely low CTE, to minimize the thermal expansion in the grips. The properties of the INVAR alloy are summarized in Table 2.

The grips were designed in such a way that they self-aligned the specimen and prevented rotation in the uncured specimen. The specimen mounts consisted of two holes which were used to hold each substrate in the proper orientation. Figure 3 shows the specimen mounting grip rods used for the test.

Table 2. Selected properties of the substrates and grip material

\begin{tabular}{|c|c|c|c|}
\hline Property & DP980 & AA7071 & INVAR \\
\hline Young's Modulus (ISO 6892-1) & $209 \mathrm{GPa}$ & $66 \mathrm{GPa}$ & $132 \mathrm{GPa}$ \\
\hline Yield Strength (ISO 6892-1) & $650 \mathrm{MPa}$ & $405 \mathrm{MPa}$ & $725 \mathrm{MPa}$ \\
\hline Coefficient of Thermal Expansion & $1.15 \mathrm{E}-5 / \mathrm{K}$ & $2.18 \mathrm{E}-5 / \mathrm{K}$ & $1.8 \mathrm{E}-6 / \mathrm{K}$ \\
\hline Thermal Conductivity & $55 \mathrm{~W} / \mathrm{m} \mathrm{K}$ & $230 \mathrm{~W} / \mathrm{m} \mathrm{K}$ & $20 \mathrm{~W} / \mathrm{m} \mathrm{K}$ \\
\hline
\end{tabular}


Measurement devices: Three systems were running in sync with each other, including (i) the DIC system for displacement measurement, (ii) a temperature logger for temperature profile, and (iii) the 50kN load cell for force measurement.

(i) Temperature measurement: Due to the design of the furnace and nature of hot air, the air at the top is always hotter than the bottom. Therefore, different portions of the grips and the specimen experience different temperature profiles. Four K-type thermocouples were attached to the top grip, top substrate, bottom substrate, and bottom grip to measure the surface temperature at four distinct points, as shown in Figure 3.

(ii) DIC system: it is an optical strain measuring technique, which makes use of cameras and image processing to derive 3D strains. The cameras capture the images of the specimen at a predefined frequency and the DIC software then compares the whole set of images (called as stages) to the reference stage, to determine the movement of the substrates with respect to time. In the test setup, the GOM Aramis 5M system DIC system was used to capture the displacement in the substrates during the paint baking cycle.

(iii) Force measurement: The top grip rod was mounted to a load cell equipped with the Instron load frame, to capture the tensile or compressive forces exerted by the specimen due to thermal expansion or contraction during the tests. 


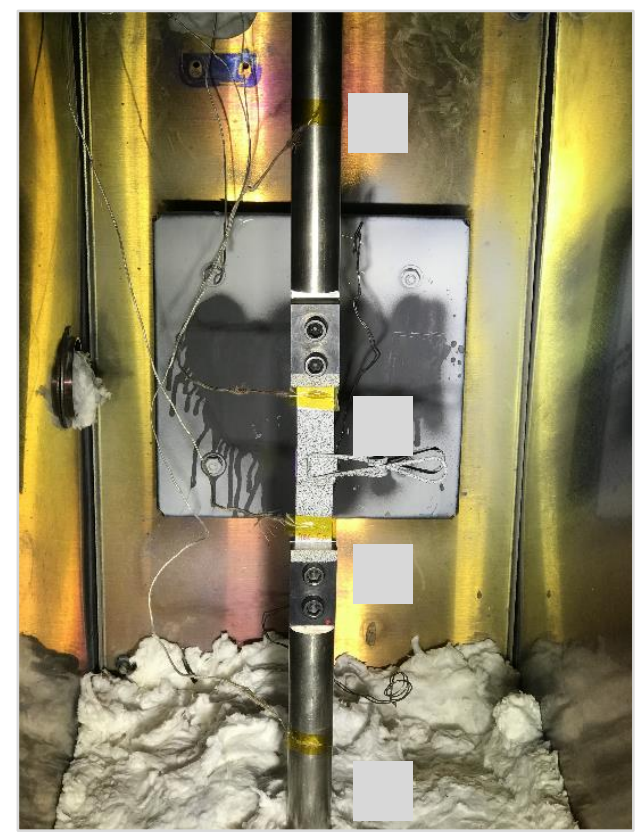

Figure 3. Specimen mounted on the INVAR grips and thermocouples attached at four locations numbered in the figure

\subsection{Test Methodology}

The experiment was performed in two stages: (i) heating phase and (ii) cooling phase.

(i) Heating phase: a single-lap shear joint was prepared by applying adhesive on the mating surfaces of the two substrates. Spacer grade soda lime glass beads of $0.30 \mathrm{~mm}$ were added to the adhesive to ensure a minimum $0.30 \mathrm{~mm}$ thickness of the adhesive bead. The specimen was held together by a paper clip. Before mounting the specimen on the grips, a target region of $50 \mathrm{~mm}$ length across the joint was painted in black and white speckle pattern as per the DIC standard, shown in Figure 1. The thermocouples were attached to the specimen and the grip rods and the furnace controller was set to $185^{\circ} \mathrm{C}$. The heating phase was performed for 40 minutes and then the furnace door was opened for the cooling phase.

(ii) Cooling Phase: In the cooling phase, the specimen was slowly cooled by natural cooling and the test was stopped when the temperature reading for all the thermocouples reached $30^{\circ} \mathrm{C}$. 
The addition of glass beads to the adhesive controls the minimum thickness of the adhesive layer, however, the actual thickness could still be more than the diameter of the glass beads. Therefore, the thickness of the adhesive joint for each specimen was measured after the test. The thickness of the adhesive bead was obtained by subtracting the thickness of the two substrates from the total joint thickness.

A picture of the complete test setup in the heating and cooling phase is shown in Figure 4.

\subsection{Results and Discussion}

The temperature data from temperature logger, displacement data from DIC, and the force data from the load cell were cross-referenced and studied together to get a holistic picture of the phenomenon induced by the thermal expansion during the adhesive curing process.

\subsubsection{Temperature profiles}

A sample of the temperature measurements recorded during the tests is shown in Figure 5. It shows the temperature ramping up in the heating phase $(0$ to $2400 \mathrm{sec}$ ) and then slowly cooling down (2400 to $11000 \mathrm{sec})$. The temperature profile of the four points was found to be the same for both substrate combinations (ST-AL and AL-AL). The temperature profile of the top and bottom substrates is nearly the same, but it is different from the temperature profile of the top and bottom grip. The top grip heats at a faster rate than the bottom grip and cools at a much slower rate. This is because of two reasons: (i) the hot air inside the furnace rises and heats the upper half of the furnace more rapidly than the lower half, (ii) the variation in the final temperature of the top grip and the bottom grip is due to the different lengths and connections of the two grip rods. As a result, two grip rods lose heat to the surroundings in dissimilar ways. 

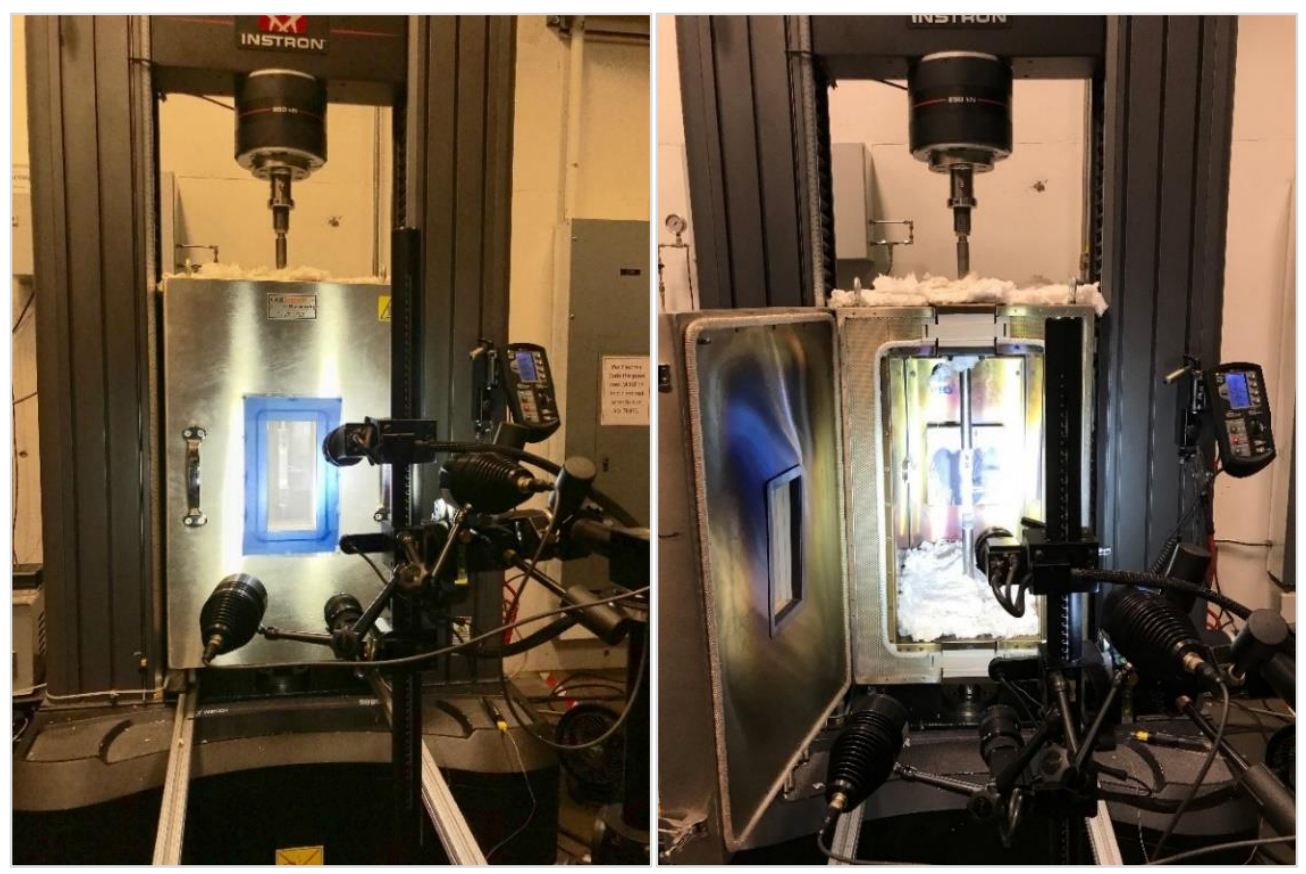

Figure 4. (a) Test setup with furnace door closed (heating phase); (b) furnace door open (cooling phase)

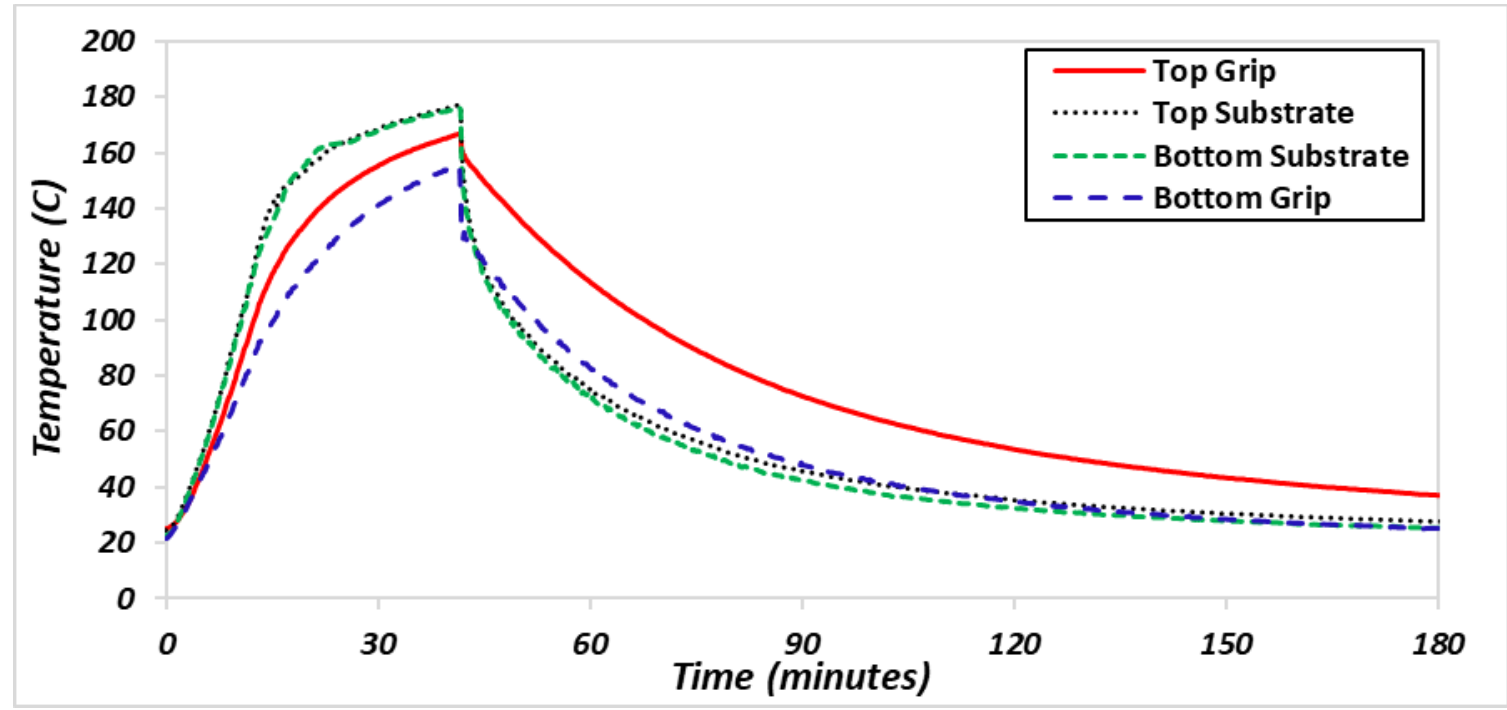

Figure 5. Surface temperature profiles obtained from the four thermocouples shown in Figure 3.

\subsubsection{Displacement and Force results}

The image series recorded for the entire paint baking cycle was processed and the $X / Y / Z$ displacement contour map for the target region was obtained. The full-field DIC Y-displacement map (shown in Figure 6) shows the movement of the substrates and the grips in the $Y$ direction at different periods during the 
paint bake cycle. To extract the displacement history in a plot, a virtual extensometer of 30mm (Figure 7) was placed in $\mathrm{Y}$ direction across the joint with the endpoints on each substrate. Although the substrates had expansion in the $\mathrm{X}$ direction as well, the magnitude of expansion was beyond the DIC measurement error. The relative $\mathrm{Y}$-displacement across the joint for three repetitions for ST-AL and AL-AL tests is shown in Figure 8.

The force measurements recorded by the load cell attached to the top grip rod are shown in Figure 9.

\subsubsection{Discussion}

The trends in the temperature profile, Y-displacement, and force measurements, when studied together, indicate the effect of the heat curing process and the behavior of the adhesive joint during the curing process.

During the heating phase, as the temperature of the two metallic substrates and the grip rods start rising, they begin to expand. The top substrate, being constrained to the grip rods at its top end, tends to move down in the negative $Y$ direction. Similarly, the bottom substrate moves upwards, in the positive $Y$ direction. This is represented by a negative relative Y-displacement in the heating phase (Figure 8). Meanwhile, the uncured adhesive is compliant at the beginning and does not pose any restrictions to the movement of the substrates, and thereby accounts for a negligible force at the beginning (Figure 9). With increasing temperature and time, the adhesive starts curing at around 1800 seconds and the adhesive modulus starts rising. Accordingly, the adhesive starts restricting the further expansion of the substrates and the load cell picks up compressive forces. The temperature of the system keeps rising until the end of the heating phase, generating further expansion in the substrates and the grips. Therefore, the $\mathrm{Y}$ displacement keeps rising in the negative direction and the compressive force keeps mounting on the adhesive.

At the onset of the cooling phase, the temperature of the system starts dropping. Due to this, the substrates and the grips begin to contract, and the direction of the displacement is reversed. The 
substrates start moving away from each other, back to their original state. The fully cured adhesive bond now starts opposing the thermal contraction and the load cell starts picking tensile forces. As a result of the bond, the substrates fail to retract to their initial state, and this is shown by a residual Y-displacement at the end of the cooling phase.

It was observed that the level of negative forces at the end of the heating phase was significantly lower than the positive forces at the end of the cooling phase. This behavior is well explained by the temperature and cure dependent properties of the adhesive. At the peak temperature, although the adhesive gets fully cured, the effect of the high temperature keeps the adhesive modulus low and the adhesive stays more compliant. At lower temperatures, the modulus of the fully cured adhesive rises sharply, and the tensile force applied by the adhesive reaches much higher levels. These tensile forces applied by the adhesive set the residual stress in the adhesive bond.

Effect of substrate combination: The $\mathrm{Y}$-displacement on $30 \mathrm{~mm}$ gauge length (GL) for AA7071 - AA7071 combination shows a higher negative peak as compared to ST-AL combination, at the end of the heating phase, owing to a higher coefficient of thermal expansion for aluminum. A higher level of thermal expansion and contraction in the aluminum substrate leads to a higher displacement across the joint and produces a higher force at the end of the cooling phase.

Effect of adhesive bondline thickness: It is known from the literature that a thin adhesive bead leads to a stiffer joint, which was also observed in this study [21]. The behavior of the joint was found to be very sensitive to the thickness of the adhesive bead. Due to the manual application of adhesive in specimen preparation, it was a challenge to ensure the same thickness for each specimen. Therefore, the thickness of each specimen was recorded after the test and the average thickness was found to be $0.32 \pm 0.02 \mathrm{~mm}$. It was found that the thickness of the adhesive bead of each sample had a relation with the final force value at the end of the cooling phase. During the heating phase, the thickness of the adhesive bondline does not affect the expansion in the substrates, therefore similar values of Delta-Y were observed at the 
end of the heating phase. At the start of the cooling phase, when the adhesive is fully cured, the specimens with a thin bondline thickness showed higher stiffness and generated higher force at the end than thicker bondline specimens.

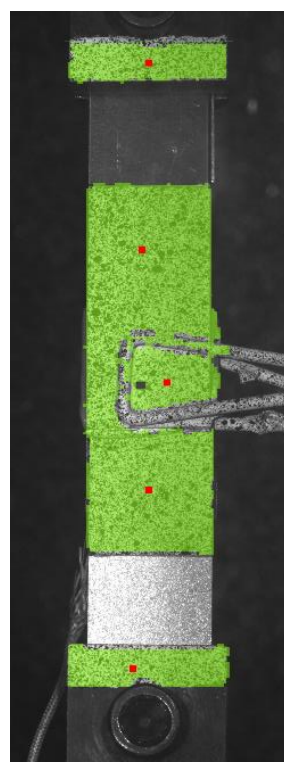

Time $=0 \mathrm{~min}$

Temperature $=25^{\circ} \mathrm{C}$

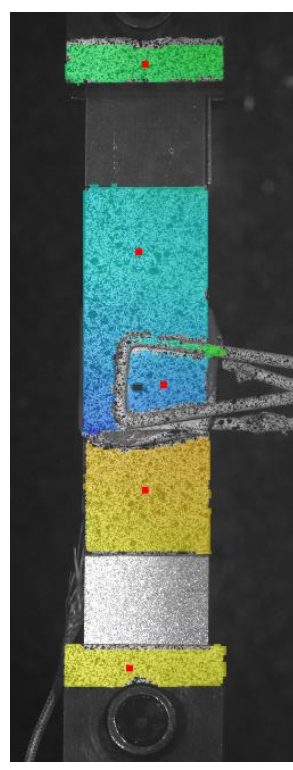

Time $=20 \mathrm{~min}$

Temperature $=160^{\circ} \mathrm{C}$

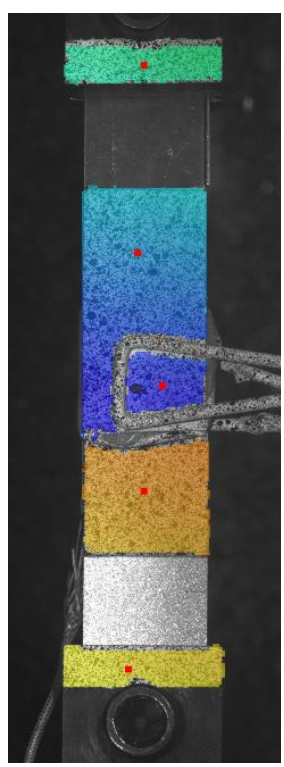

Time $=40 \mathrm{~min}$

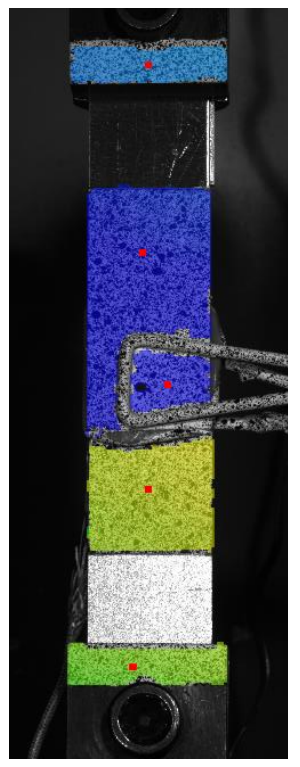

Time $=45 \mathrm{~min}$

Temperature $=115^{\circ} \mathrm{C}$
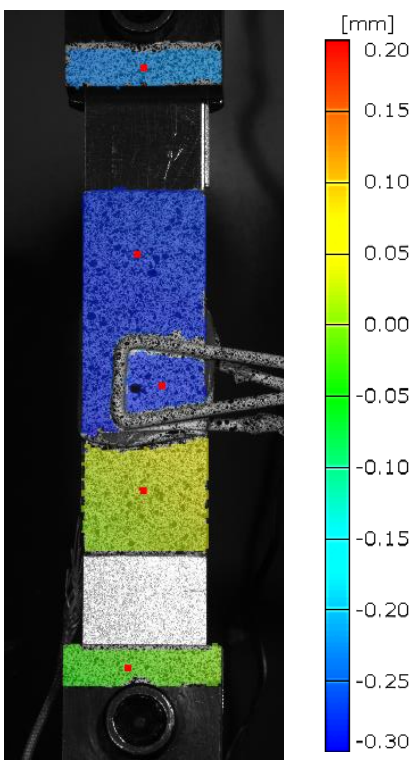

Time $=85 \mathrm{~min}$

Temperature $=45^{\circ} \mathrm{C}$

Figure 6. Y-displacement contour maps obtained from processing the DIC results

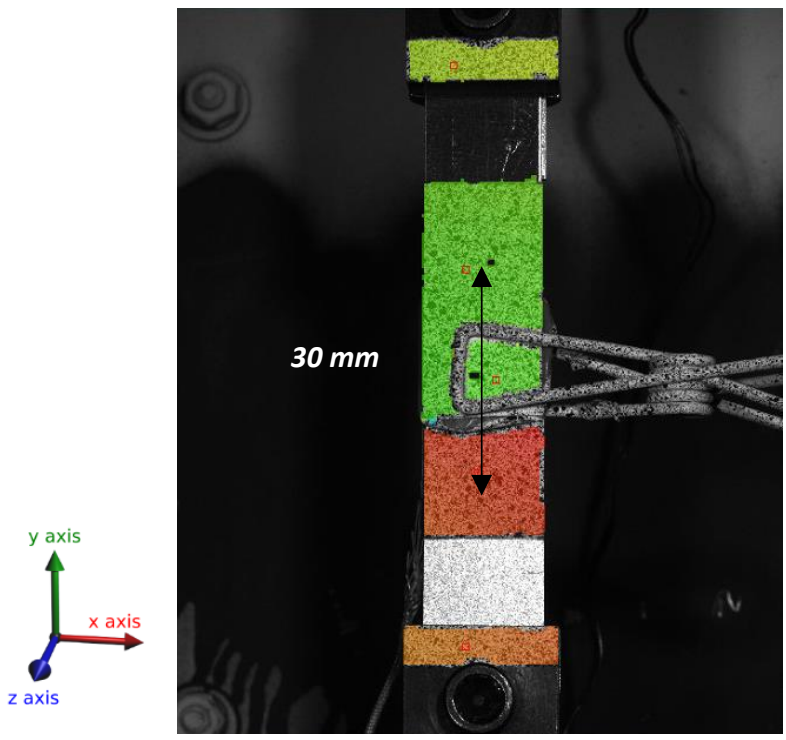

Figure 7. Virtual extensometer of $30 \mathrm{~mm}$ length across the adhesive joint 


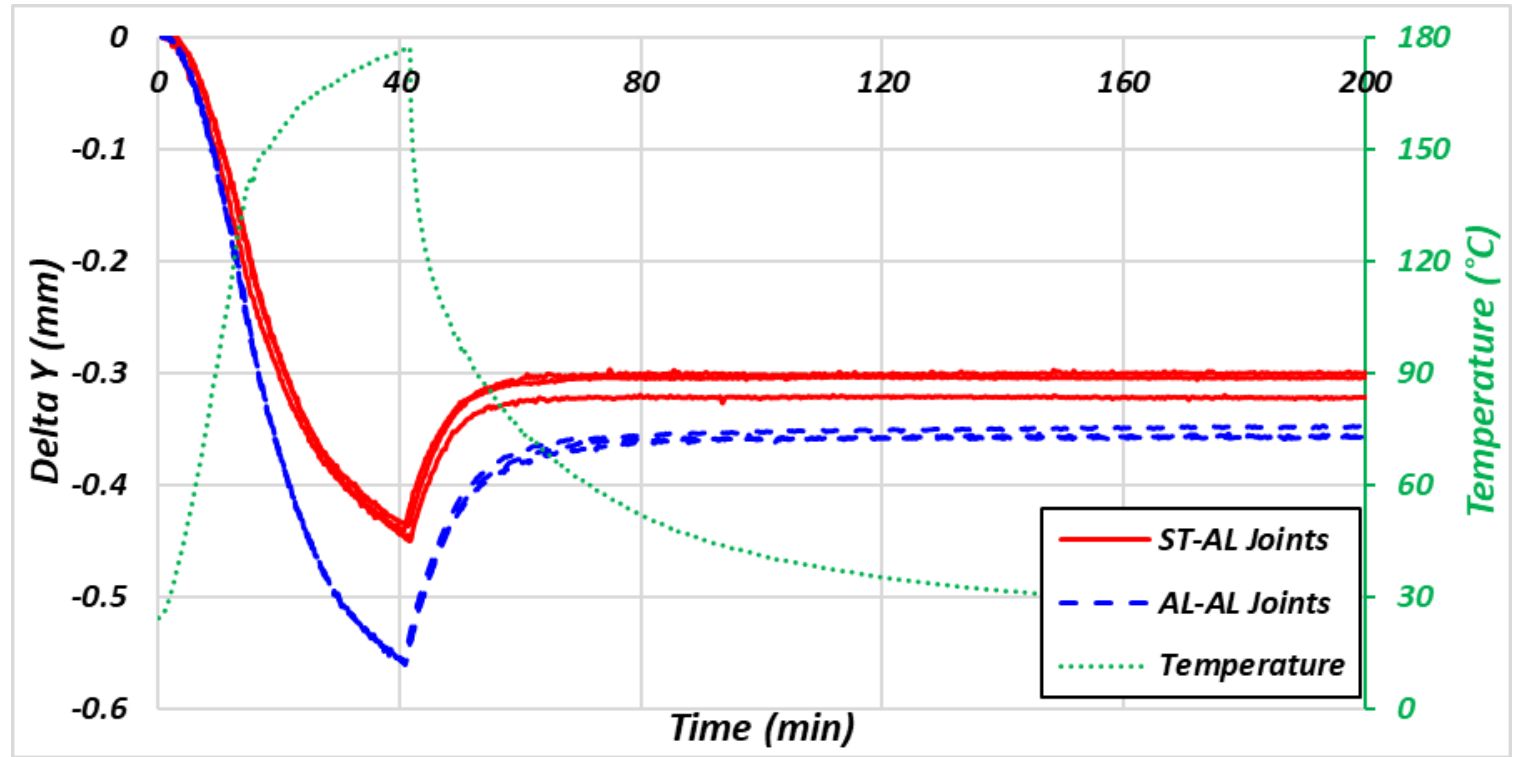

Figure 8. Y-displacement on $30 \mathrm{~mm}$ gauge length across the joint for ST-AL and AL-AL tests with temperature on the secondary vertical axis

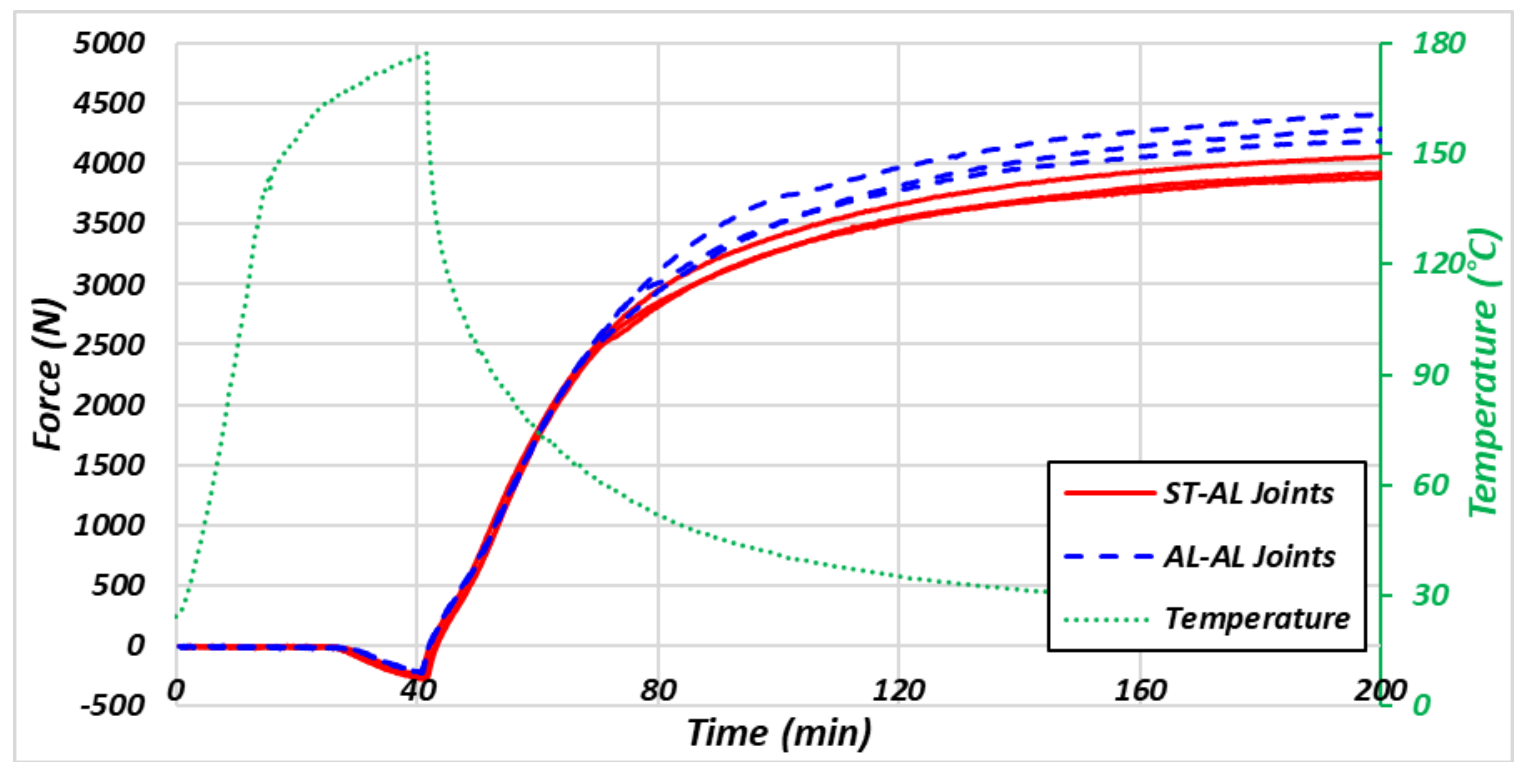

Figure 9. Force measurements during the curing cycle for ST-AL and AL-AL tests with temperature on the secondary vertical axis

Based on the results of this test, it is evident that the manufacturing process of a heat-cured adhesive joint puts residual stresses on the adhesive bond and causes distortion in the substrates. The effects of 
thermal expansion during the curing process will be much more magnified on a full vehicle level. Therefore, it is important to understand the significance of these process-induced residual stresses on the performance of the joint, which is discussed in the next section.

\section{EXPERIMENTS TO EVALUATE THE EFFECTS OF RESIDUAL STRESS ON JOINT PERFORMANCE}

In the last set of experiments, it was established that thermal expansion in the metallic substrates induces residual stress in the adhesive-bonded joint during the heat curing process. In this section, the single lap shear joints with residual stresses were pulled in tension and the results were compared to the performance of the joints without residual stresses. The joints were tested at multiple shear strain rates, ranging from a very slow rate $0.005 / \mathrm{s}$ to intermediate-high rate $50 / \mathrm{s}$. The test results revealed the effects of residual stress at high rates which will help in predicting the joint behavior at the time of events like a crash.

\subsection{Specimen geometry and materials}

The tests were run on a single lap shear specimen geometry discussed in Section 2.1. The tests were performed on the same adhesive Henkel EP 5089 and a multi-material substrate combination of ST-AL.

Two types of samples were prepared for the tests: stress-free samples, and samples with residual stress.

The stress-free samples were prepared by curing the specimens without constraining the substrates, to allow free movement in the substrates induced by thermal expansions during the curing cycle. This allows free expansion of the substrates during the heating phase of the curing cycle, and then free contraction during the cooling phase of the curing cycle, causing no relative displacement across the adhesive joint. Having no displacement across the fully cured adhesive joint (in the cooling phase) ensures stress-free 
adhesive bonded samples. The specimens were cured for 30 minutes at $180^{\circ} \mathrm{C}$. Figure 10 shows the method for specimen preparation.
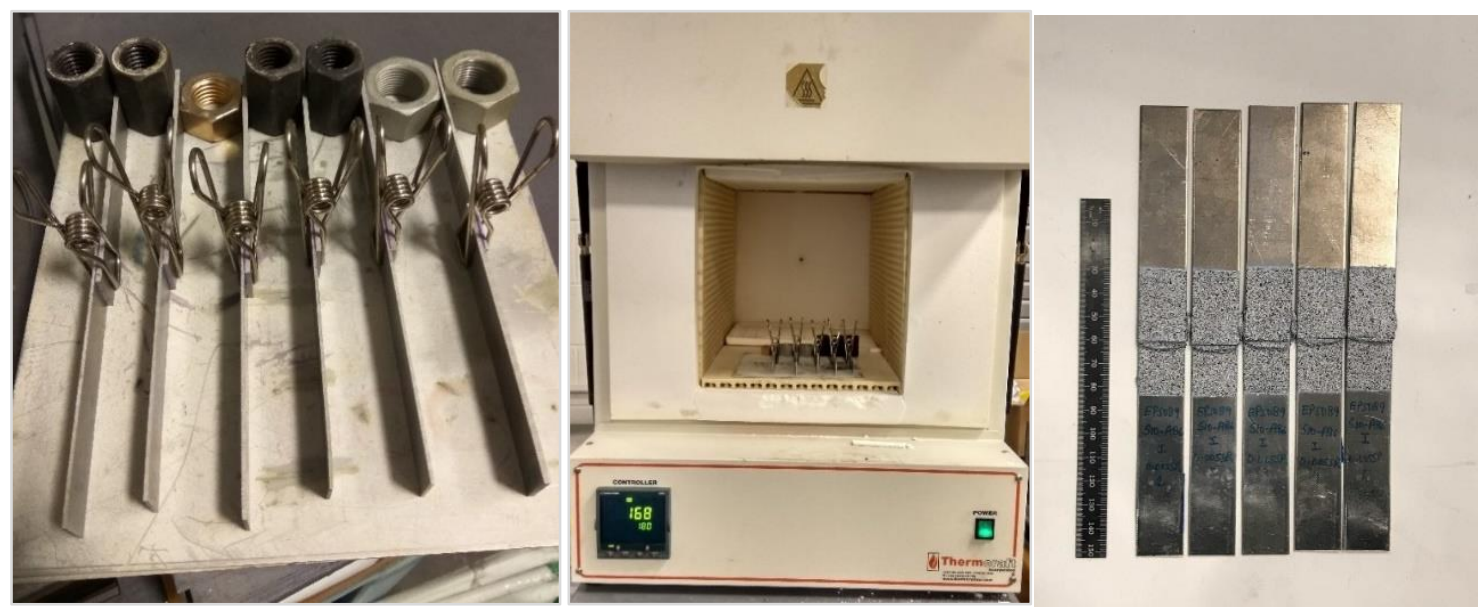

Figure 10. Process used for producing Stress-free adhesive-bonded single lap shear specimens

The samples with residual stresses were prepared on the same setup and following the same procedure as discussed in Sections 2.2 and 2.3.

\subsection{Calculation of Shear Strain Rate}

The shear strain across the lap shear joint is dependent upon the thickness of the adhesive bead in the joint. To determine the testing crosshead speed and analyze the results, the measured average thickness $(0.32 \mathrm{~mm})$ of the adhesive bond was used in the calculation. The shear strain rate was calculated using the formula:

$$
\text { Shear Strain Rate }=\frac{\text { Crosshead Speed }}{\text { Joint Thickness }}
$$

First, the theoretical crosshead speed was calculated based on the intended shear strain rate and a few preliminary tests were run. The displacement across the joint from the preliminary tests was used to determine the actual shear strain rate of the test. The test shear strain rate was then used to obtain the machine compliance factor and the crosshead speed was adjusted to obtain the exact shear strain rate. 
For example, for a shear strain rate of $0.5 / \mathrm{s}$, the theoretically calculated crosshead speed was 0.15 $\mathrm{mm} / \mathrm{s}$, which was later adjusted to $1.10 \mathrm{~mm} / \mathrm{s}$ to account for the compliance in the testing machine.

\subsection{Experimental Setup}

The tests were performed on two different experimental setups for the different shear strain rates. The tests at $0.005 / \mathrm{s}$ and $0.5 / \mathrm{s}$ were done on an Instron quasi-static electromechanical load frame with a $50 \mathrm{kN}$ load cell. The single-lap shear joint specimen was held using wedge grips and the strain measurement was done using the GOM Aramis 3D DIC system which is capable of capturing images at up to 125 frames per second. Figure 11 shows the experimental setup and the specimen mounted on the wedge grips.
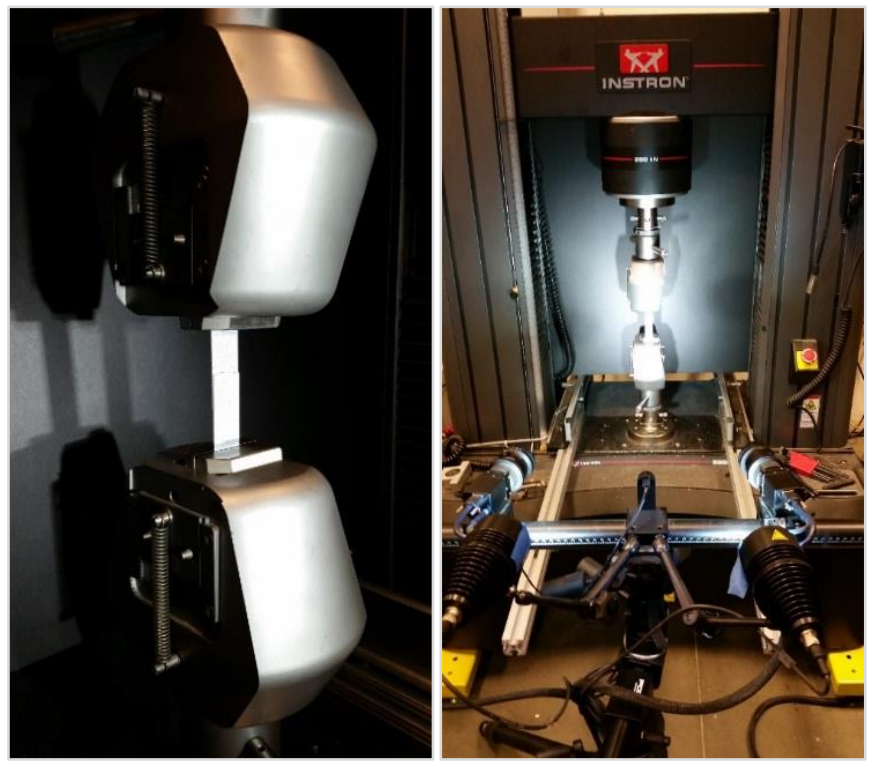

Figure 11. Experimental setup for testing at $0.005 / \mathrm{s}$ and $0.5 / \mathrm{s}$ shear strain rates

The tests at a shear strain rate of 50/s were performed on an Instron servo-hydraulic machine with a 50kN load cell which was capable of running at higher speeds. The setup had a pair of hydraulic wedge grips and the strain measurement was done using Photron AX200 high-speed camera at 100,000 frames per second. The experimental setup for high-speed testing is shown in Figure 12. 


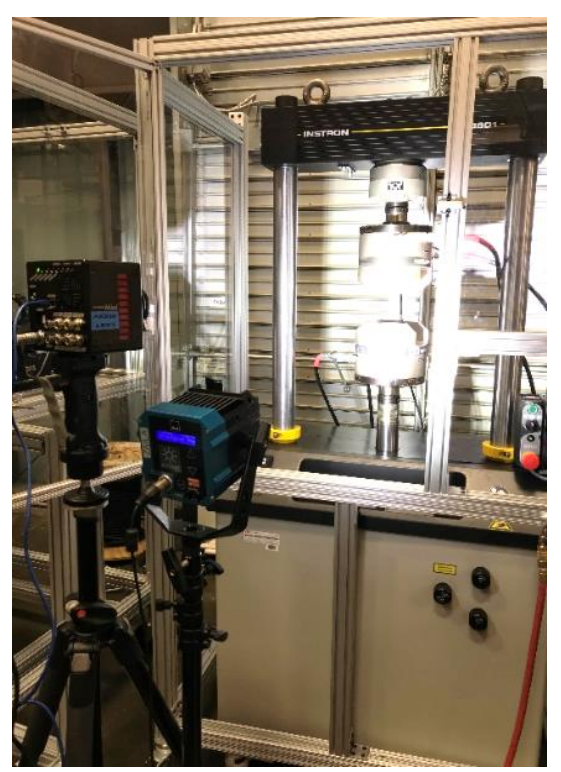

Figure 12. Experimental setup for testing at $50 / \mathrm{s}$ shear strain rate

\subsection{Results}

Force-Strain Plots: The DIC results were processed to obtain the displacement across the joint. A virtual extensometer of $30 \mathrm{~mm}$ was drawn with one end on each substrate in order to keep the adhesive joint within the extensometer length. Shear strain is defined as the ratio of change in the Y-length (Delta $L(y))$ of the extensometer to the pre-measured bond thickness. The given formula calculates the global shear strain across the adhesive joint.

$$
\text { Shear Strain }=\frac{\text { Delta } L(y)}{\text { Joint Thickness }}
$$

The force-shear strain curves for the tensile tests of lap shear adhesive joints for the three shear strain rates are given in Figure 13, Figure 14 and Figure 15., respectively. 


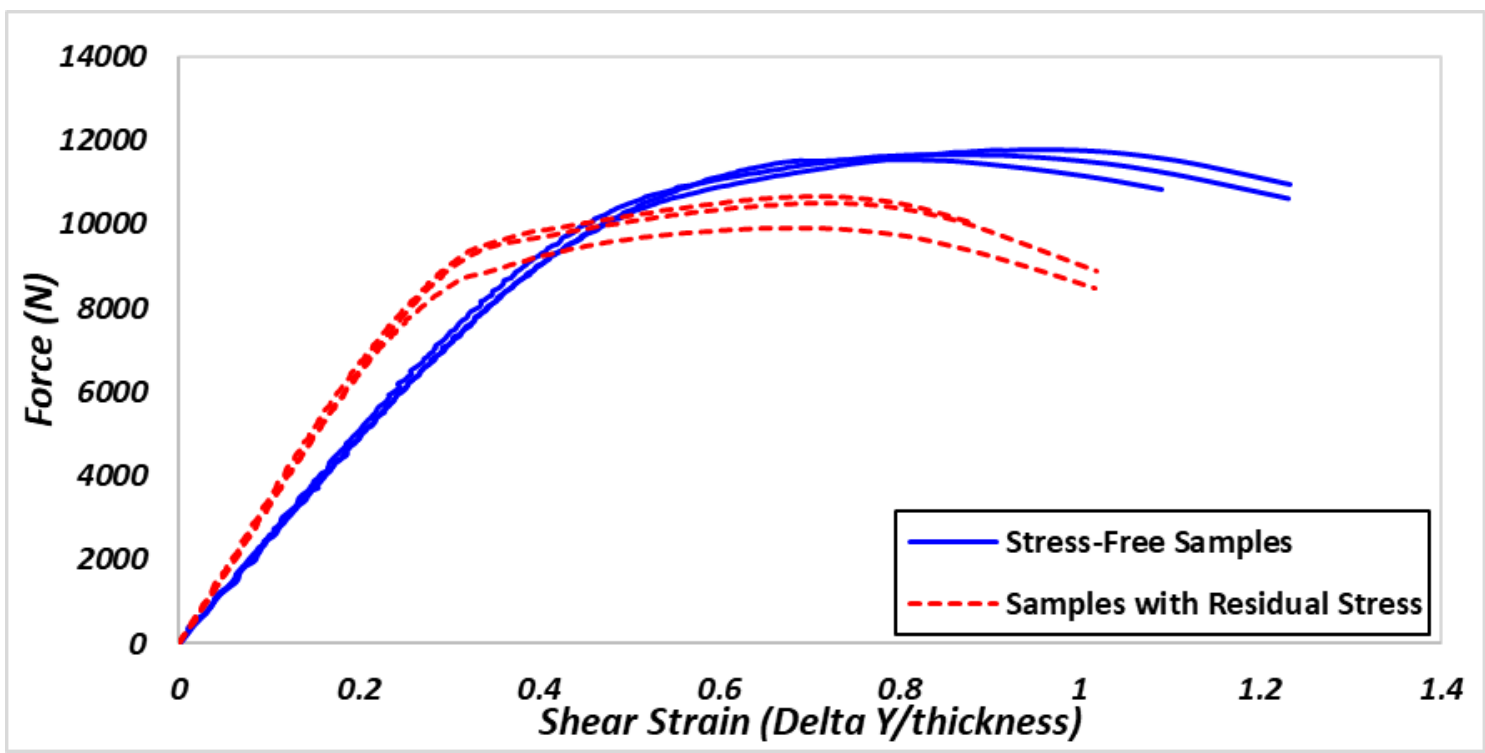

Figure 13. Force-Strain curves for ST-AL lap-shear specimens at a shear strain rate of $0.005 / \mathrm{s}$ for stress-

free specimens in solid blue and specimens with residual stress in dashed red

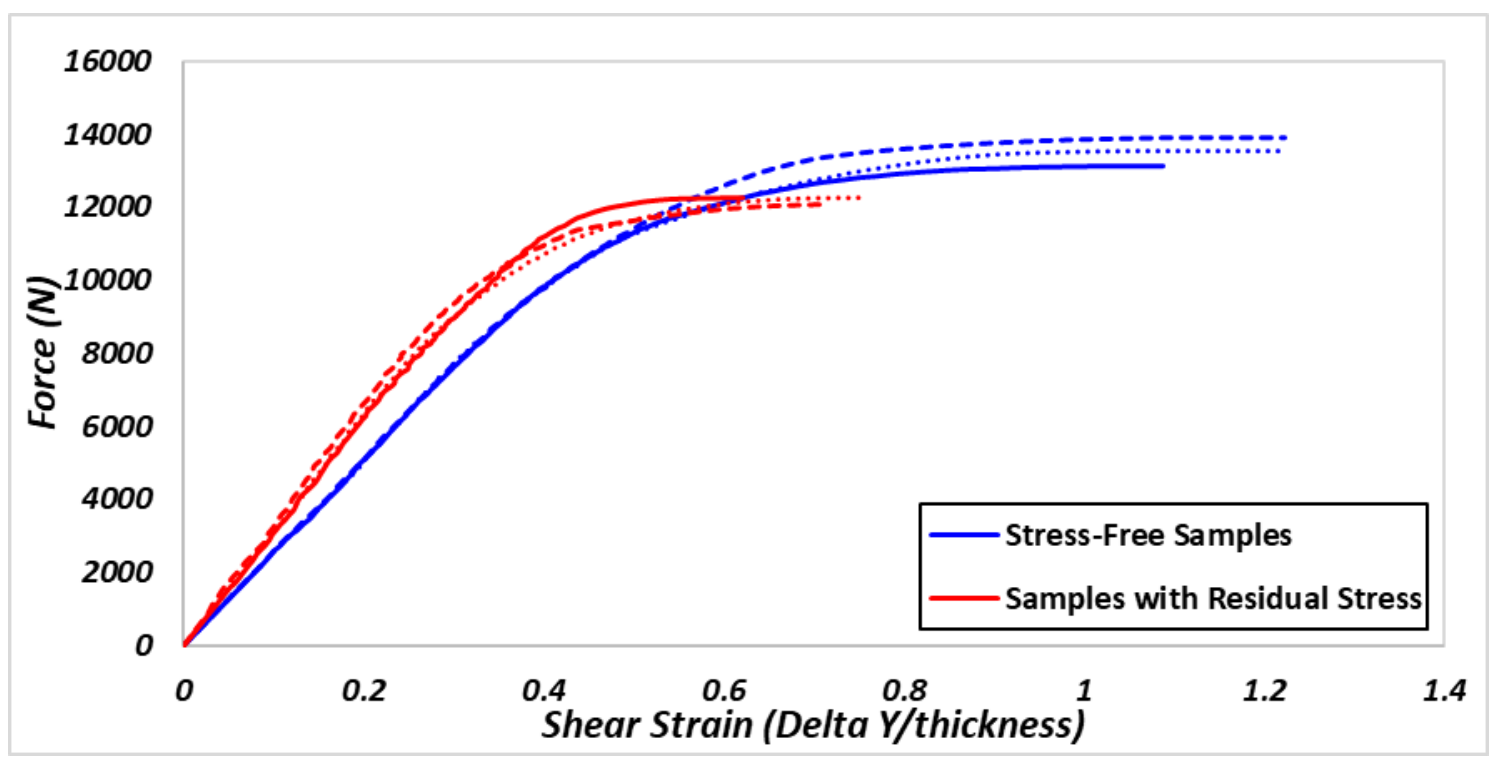

Figure 14. Force-Strain curves for ST-AL lap-shear specimens at a shear strain rate of $0.5 / \mathrm{s}$ for stress-free specimens in solid blue and specimens with residual stress in dashed red 


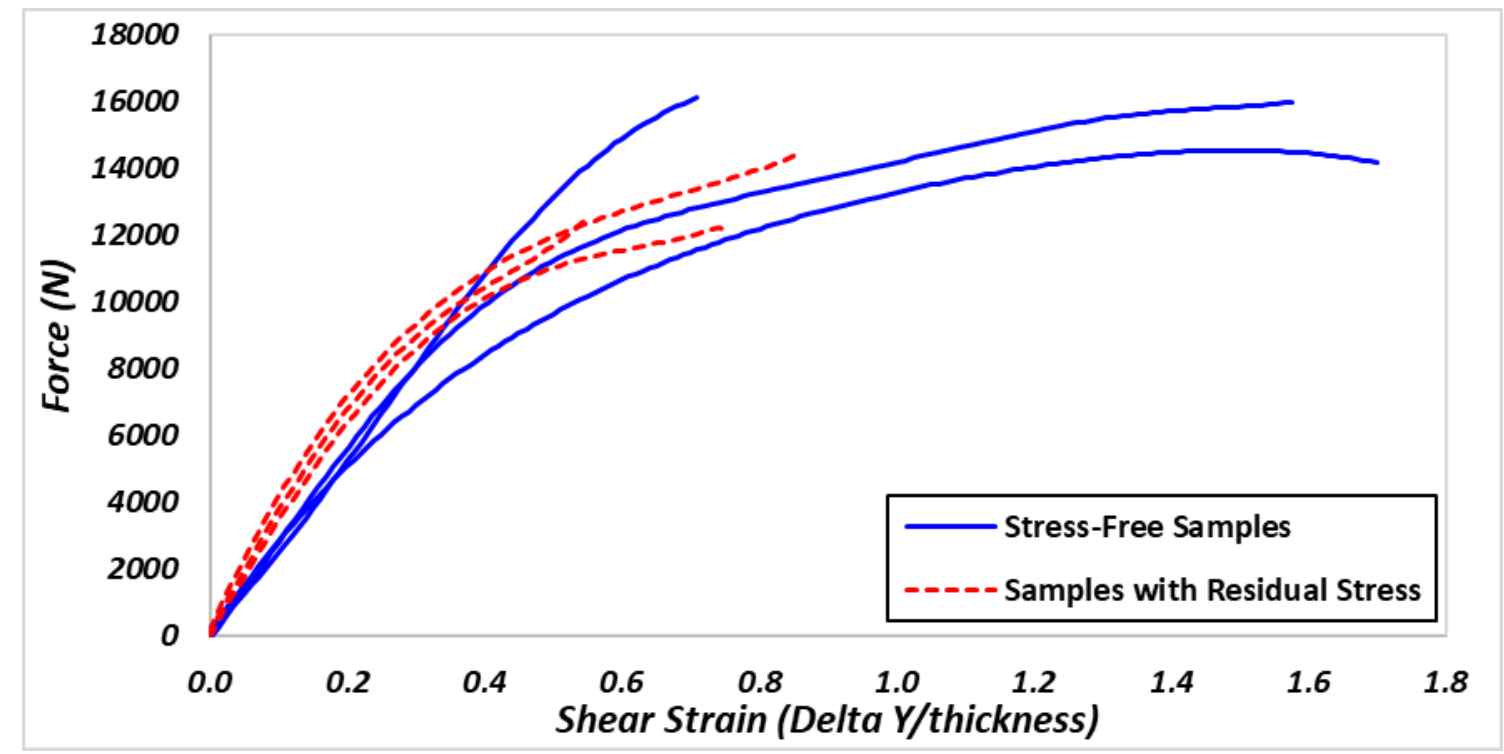

Figure 15. Force-Strain curves for ST-AL lap-shear specimens at a shear strain rate of 50/s for stress-free specimens in solid blue and specimens with residual stress in dashed red

Failure Modes: The samples were analyzed after the tests and the failure modes were visually studied. It was found that the samples had a cohesive failure for all the strain rates. Figure 16 shows the failure mode in the tested samples.
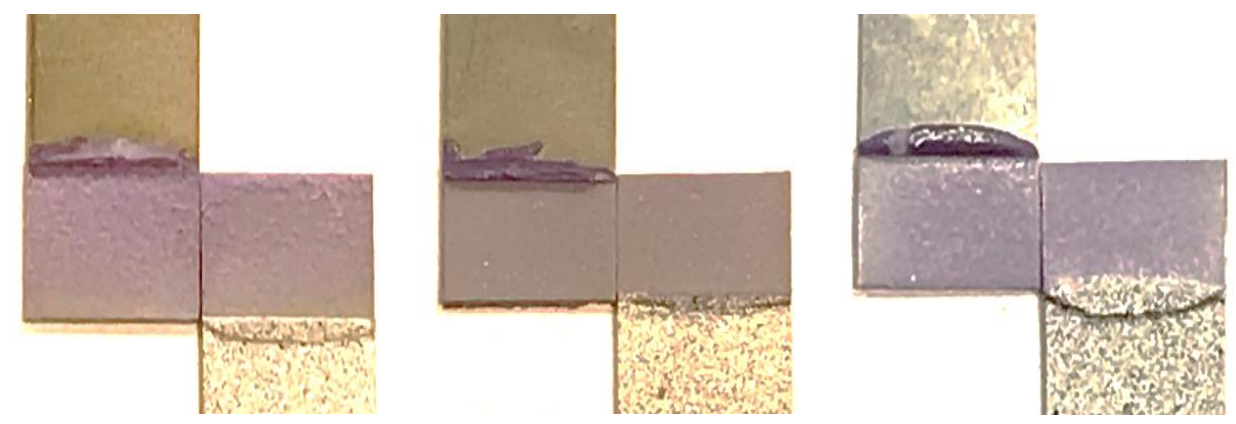

Figure 16. Failure Modes in the tested lap-shear specimens at (left to right) (a) $0.005 / \mathrm{s}$; (b) $0.5 / \mathrm{s}$; (c) $50 / \mathrm{s}$

\subsection{Discussion}

The force-shear strain curves for tension tests of lap shear joints at all three strain rates show linear nature at the beginning followed by some degree of plasticity. It was observed that the maximum force in the tests at all speeds was less than the yielding force of the substrates as shown in Figure 2. Hence, the 
displacement across the virtual extensometer captured by DIC was solely dependent on the adhesive bond with minimum elongation in the substrates, and the force measured in the test was not limited by the choice of substrates. The following key conclusions were derived from the tests:

(i) An important difference between the curves for stress-free and samples with residual stress is the initial slope of the curve. The stiffness of the specimens with residual stress is higher than the stress-free specimens for all the strain rates.

(ii) Another noticeable effect of residual stresses is the difference in maximum force to failure. The maximum force for the stressed specimen is lower than the stress-free specimens for all the shear strain rates.

(iii) There is a drop in the maximum shear strain to failure when the specimens have residual stress as compared to stress-free specimens.

(iv) The results from the tension tests of single-lap shear joints show large strain rate sensitivity. The maximum force to failure increases by $19 \%$ for a shear strain rate increase of $0.005 / \mathrm{s}$ to $0.5 / \mathrm{s}$ and rises to $39 \%$ when the shear strain rate increases from $0.005 / \mathrm{s}$ to $50 / \mathrm{s}$ for the stressfree specimens. A similar increase in maximum force was observed for specimens with residual stress. A comparison of the curves for different strain rates for stress-free and with residual stress specimens is shown in Figure 17. 


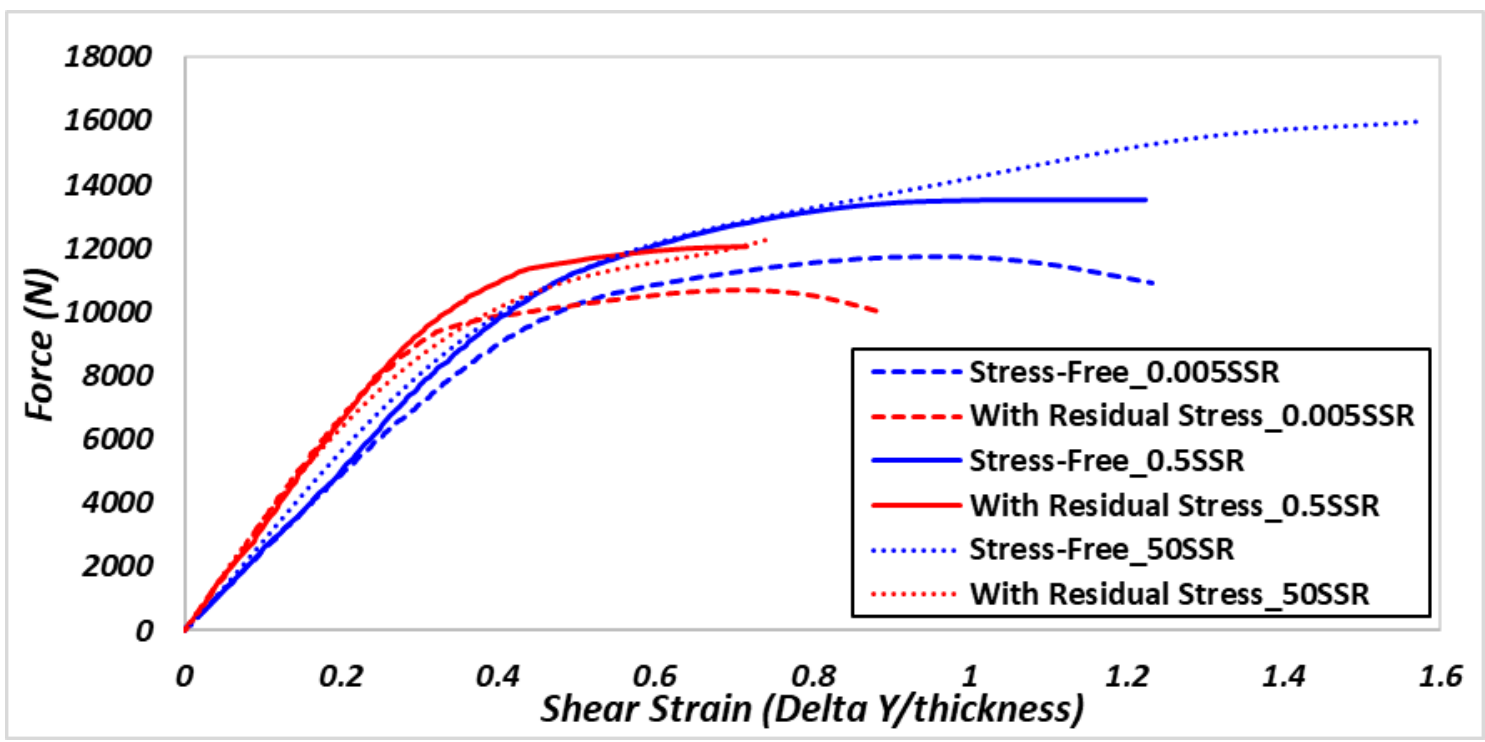

Figure 17. Comparison of force vs. strain curves for ST-AL lap-shear specimens at shear strain rates of $0.005 / \mathrm{s}, 0.5 / \mathrm{s}$ and $50 / \mathrm{s}$ for stress-free specimens in blue and specimens with residual stress in red

\section{CONCLUSIONS}

In this paper, two sets of experiments and the corresponding results were discussed. The first set of experiments was an innovative approach using 3D DIC system to study the effects of thermal expansion on the adhesive joint during the heat curing process. The experimental setup allowed the curing of an adhesive bonded single lap shear joint in a specialized oven while monitoring the thermal expansion and contraction in the substrates in the heating and the cooling phase. The experimental results shed light on the behavior of the adhesive-bonded joint for a multi-material substrate combination and a similar material substrate combination during the curing process. It was confirmed that the adhesive-bonded joint is subjected to residual stresses at the end of the curing process due to thermal expansion in the substrates. The presented experimental technique paves the path for quantifying the global residual stress levels in the adhesive bond, which can be explored in future work.

The second set of experiments presented the effect of residual stresses on the performance of a single lap shear joint. The single-lap shear joints were prepared in two ways: (i) Stress-free samples, and (ii) 
Samples with residual stress. The performance of the joint with residual stresses was compared to stress-

free joints by pulling the single lap shear joints in tension at varying strain rates. The results indicated large strain-rate sensitivity as the maximum force to failure increases with an increase in the shear strain-rate.

The study showed that the residual stresses hinder the peak performance of the joint by limiting the maximum force to failure and the total strain to failure. Based on the derived results, it is necessary to include the effects of manufacturing induced effects in the design process of adhesively bonded structures. Both the tests help in understanding the behavior of the residual stresses on the joint and provide quantifiable parameters, which can be utilized for the validation of adhesive material models. The effects of manufacturing induced residual stresses in the adhesive joint, if included in the modeling of the adhesive joint, will lead to more accurate prediction of the joint performance in simple as well as complex structures.

For future work, it will be interesting to study the effect of aging on the properties of the adhesive bond. Since adhesives are viscoelastic materials, the residual stresses are expected to relax with time, and it would be interesting to study the change in the behavior of the joint with time.

\section{REFERENCES}

1. Banea, M.D. and L.F.M. da Silva, The effect of temperature on the mechanical properties of adhesives for the automotive industry. Proceedings of the Institution of Mechanical Engineers, Part L: Journal of Materials: Design and Applications, 2010. 224(2): p. 51-62.

2. Marques, E.A.S., et al., Adhesive Joints for Low- and High-Temperature Use: An Overview. The Journal of Adhesion, 2014. 91(7): p. 556-585.

3. Banea, M.D. and L.F.M. da Silva, Adhesively bonded joints in composite materials: An overview. Proceedings of the Institution of Mechanical Engineers, Part L: Journal of Materials: Design and Applications, 2009. 223(1): p. 1-18.

4. Gould, J.E., Challenges and Advances in Resistance Spot Welding Aluminum Sheet. Resistance and Solid State Welding, 2014.

5. A.M. Pereira(1)*, J.A.M.F., F.V. Antunes(2) and P.J. Bártolo(1), Strength of aluminium resistance spot welded and weldbonded joints. C. Tecn. Mat. v.22 n.3-4, 2010.

6. Baohua Changa, Y.S., *, Liangqing Lub, Studies on the stress distribution and fatigue behavior of weld-bonded lap shear joints. Journal of Materials Processing Technology, 2001. 108: p. 307313. 
7. Offle, S., Automotive Oven Temperature Profiling - the Key to Paint Shop Performance! Fluke Process Instruments, Public Report, 20016.

8. Reedy, E.D. and T.R. Guess, Butt joint strength: effect of residual stress and stress relaxation. Journal of Adhesion Science and Technology, 1996. 10(1): p. 33-45.

9. Kim, Y.G. and D.G. Lee, Influence of Fabrication Residual Thermal Stresses on Rubber-toughened Adhesive Tubular Single Lap Steel-Steel Joints under Tensile Load. The Journal of Adhesion, 1998. 65(1-4): p. 163-185.

10. M. Kemal Apalak *, R.G., On non-linear thermal stresses in an adhesively bonded single lap joint. Computers and Structures, 2002. 80: p. 85-98.

11. Yu, Y., I.A. Ashcroft, and G. Swallowe, An experimental investigation of residual stresses in an epoxy-steel laminate. International Journal of Adhesion and Adhesives, 2006. 26(7): p. 511-519.

12. Jamie M. Kropka, M.E.S.a.R.S.C., Role of Residual Stress on the Strength of Adhesive Joints. Sandia National Laboratories, 2013. SAND2013-10717C.

13. Meschut, G., O. Hahn, and D. Teutenberg, Influence of the curing process on joint strength of a toughened heat-curing adhesive. Welding in the World, 2014. 59(2): p. 209-216.

14. Ma, C., et al., Study of the Effect of Curing Residual Stress on the Bonding Strength of the Single Lap Joint Using a High-Temperature Phosphate Adhesive. Materials (Basel), 2018. 11(7).

15. da Silva, L.F.M. and R.D. Adams, Stress-free temperature in a mixed-adhesive joint. Journal of Adhesion Science and Technology, 2006. 20(15): p. 1705-1726.

16. da Silva, L.F.M. and R.D. Adams, Adhesive joints at high and low temperatures using similar and dissimilar adherends and dual adhesives. International Journal of Adhesion and Adhesives, 2007. 27(3): p. 216-226.

17. da Silva, L.F.M. and R.D. Adams, Joint strength predictions for adhesive joints to be used over a wide temperature range. International Journal of Adhesion and Adhesives, 2007. 27(5): p. 362379.

18. Dietrich, R., Thermal stress in the paint shop oven process (Delta-Alpha). Proceedings of automotive circle international, 2014: p. 04-02.

19. Regensburger, J., F. Biesdorf, and C. Albiez, Aluminium Roof Optimisation in the New Audi Q7. ATZ worldwide, 2015. 117(11): p. 4-9.

20. R.A. Dickie*, D.R.B., S.M. Ward, D.A. Wagner, Modeling paint and adhesive cure in automotive applications. Progress in Organic Coatings, 1997. 31 (1997) 209-216.

21. Castagnetti, D., A. Spaggiari, and E. Dragoni, Effect of bondline thickness on the static strength of structural adhesives under nearly-homogeneous shear stresses. The Journal of Adhesion, 2011. 87(7-8): p. 780-803. 